\title{
The Near Death Experience as a Product of Isolated Subcortical Brain Function
}

\author{
George E. Wettach, M.D. \\ San Francisco General Hospital \\ University of California, San Francisco
}

ABSTRACT: This paper attempts to show that the sequence of a typical near death experience (NDE) is predictable and reproducible, enough to suggest that the NDE is a symptom of a specific altered mental state seen in a large number of medical and surgical conditions. I attempt to explain on an anatomical, physiologic, and psychological basis how NDEs might be caused, and suggest that NDEs might even be the basis of religion.

I also describe an NDE of a 38-year-old insulin-dependent diabetic who developed hypoglycemia secondary to a lack of caloric intake to support her daily insulin usage. She did not appear to be life-threatened from a cardiovascular standpoint. During the hypoglycemic spell, the patient appeared to be in rapid eye movement (REM) sleep. Following resuscitation with an intravenous injection of dextrose, the patient returned to a normal mental status, but recounted a typical NDE.

Unusual psychic experiences associated with life-threatening medical and surgical conditions, involving reversible near-death situations, have become commonplace in a number of popular books written over the past two decades. The first such book, Raymond Moody's bestseller, Life After Life (Moody, 1975), and At the Hour of Death (Osis and Haraldsson, 1977) by Karlis Osis and Erlendur Haraldsson, documented hundreds of medical cases involving patients who had been pronounced clinically dead following cardiac arrest or overwhelming trauma, but survived with the help of medical and surgical interventions. More recently, personal near-death experiences (NDEs) were chronicled in the bestsellers Embraced by the Light (Eadie and Taylor,

George E. Wettach, M.D., is Clinical Instructor of Medicine at the University of California, San Francisco. Reprint requests should be addressed to Dr. Wettach at P.O. Box 395, Moffett Field, California 94035-0395; e-mail: telemed@usa.net. 
1992) and Saved by the Light (Brinkley and Perry, 1994). Most of these individuals underwent unbelievable psychological and profound perceptual experiences of a religious, metaphysical, and/or parapsychological nature. They seemed to take a trip into a world of "nonordinary reality." In most instances, their psychic experiences followed a reasonably structured sequence, although the sequence may be slightly altered in its order for some individuals.

In his early works, Moody suggested that these trips justified the conclusion from a scientific standpoint that heaven, or a "life after," exist. However, in the practice of medicine, when a large series of patients report or experience signs and symptoms that are held in common, it is logical to conclude that such signs and symptoms are based on some physiological principle. Using scientific logic, could it be possible to develop a hypothesis centered in cerebral function or psychological processing within the brain that would explain the strange psychic experiences that many patients undergo as they come close to death?

The following case report describes an insulin-dependent, diabetic woman who underwent a typical "life after death" experience during a bout of hypoglycemic coma that was successfully treated with the use of an intravenous 50 percent dextrose injection. Of interest in the case is the fact that the physician and paramedics who evaluated the patient during a prehospital care episode at the patient's home never noted any evidence that her vital signs were abnormal, and the treating team could not justify the diagnosis of clinical death.

\section{Case Report}

Ms. B. is a 38-year-old African-American woman who was seen in her home by a local emergency medical service because her relatives had noted her to have a grand mal seizure. She remained unresponsive after the seizure.

Two years prior to that seizure, Ms. B. had been treated for a freshly diagnosed cardiac condition that had presented with frank angina pectoris, for which she took 10 milligrams of propranolol orally, four times per day. Also, according to the relatives, one year prior to this seizure, she had been taken to a hospital emergency room for a similar episode and "given a shot in her veins to bring her around."

When the paramedics and their "ride-along" medical director arrived, Ms. B. was lying quietly on her bed without evidence of trauma or airway obstruction. Her pulse was 88 beats/minute, full and regular; her blood pressure was $110 / 80$; and her respiratory rate was $20 /$ minute without 
distress. Her pupils were normal, equal, and reactive to light. Rapid eye movements were obvious to all observers. Examination of the heart and lungs was normal, and all extremities were flaccid on neurologic exam.

Blood was drawn at the scene and a Dextrostix determination revealed an estimated blood sugar of 40 milligrams $/ 100$ milliliters of blood. An intravenous line with $250 \mathrm{cc}$ of 5 percent dextrose and water was started and two ampules of 50 percent dextrose were pushed intravenously. Ms. B. recovered and became alert without observable complications. She was transferred to the emergency room of a large, urban, level I trauma center. The diagnosis of hypoglycemia secondary to insulin reaction and poor carbohydrate intake, masked by the use of propranolol, was established. Other than the threat to life that a bout of hypoglycemia poses to any patient, no signs of frank impending death were noted at any time.

At the hospital Ms. B. was asked if she had experienced any unusual events while she was comatose. To this questioning, she giggled and smiled shyly. The examiner then reassured her that it would be acceptable to discuss any strange perception she might have experienced, and that he would not judge her story crazy or mock her comments. With this reassurance, Ms. B. told the following story without being led by the physician:

I heard my relatives say that I was sick and I felt that I must be dying. I became very scared. I next felt as if I was being squeezed all over my body-maybe being squeezed out of some place. I looked up and saw a very bright light. I noted that I was very happy and began to sing right along with some very beautiful music. I saw a figure ahead of me. The figure looked like God, or maybe Jesus. Then I woke up.

\section{Discussion}

\section{The Prototypical NDE}

Moody (1975) presented a composite model of the NDE from a large series of experiencers, which includes the following features: the individual (1) experiences clinical death; (2) hears the voices of doctors or relatives as he or she departs; (3) hears an uncomfortable, loud, buzzing or ringing noise; (4) moves through a long dark tunnel toward a bright light; (5) experiences moving outside the normal, physical body, phenomena commonly termed "astral projection" in the metaphysical literature; (6) sees the physical body from an external vantagepoint; (7) experiences a state of emotional upheaval; (8) accommodates to a 
new, strange nonphysical body and may discover the power of mental telepathy; (9) visualizes dead spirits or dead relatives, who may act as guides; (10) has a feeling of great warmth; (11) meets a "being of light," which may resemble God or Jesus and who desires to pass judgment on the individual; (12) perceives an instantaneous playback of the events of his or her life; (13) approaches some type of barrier between life and death; (14) finds he or she must return to life while being overcome with joy, love and peace; and (15) reunites with the physical body and becomes conscious.

\section{An Evolutionary Brain Model}

What does the above sequence represent? To Elisabeth Kübler-Ross, who wrote the forward to Moody's Life After Life (Moody, 1975, p. xi), it confirms 2,000 years of religious teaching. To a psychologist, it might represent a hypnagogic hallucination. But, could the near-death sequence be used to design a hypothetical physiologic model?

The human brain and spinal cord have slowly evolved over millions of years, and today, the central nervous system is a net result of anatomical contributions of each step in that progression. Simple, early reflex activities of the primitive spinal cord progressed to the medulla and the sophisticated respiratory and cardiac cycles seen in fish and amphibians. The next progression placed a pons and paleocortex in a reptile, a primitive brain with intuitive-cognitive powers. Soon to follow in mammals, a cerebral cortex with advanced analytical skills was functioning. From an energy standpoint the above evolution has progressed from neurologic structures such as peripheral nerves requiring low metabolic states for survival and function to the cerebral cortex, which begins to undergo dysfunction and clinical death if deprived of blood supply, rich in oxygen and essential nutrients, for more than 10 seconds. There is some evidence that cerebral ischemia alone can precipitate some features of NDEs. James Whinnery (1997) has described NDE-like experiences in healthy jet pilots who blacked out while undergoing highacceleration centrifuge experiments. It is apparent that these young pilots do not die, but they probably experience short periods of cerebral ischemia that precipitates the NDE-like experience while they are unconscious.

The human nervous system is a result of fusion of the evolution of all brains from many phyla. Each phylum has a brain based on a given metabolic rate and ability to survive a given environmental range of 
extremes. As a result of the fusion of brains from earlier phylogenetic forms, the cognitive portion of the human brain is made up of a "reptilian brain," consisting of the pons, geniculate bodies, and a portion of the occipital area (the so-called PGO area), and a "mammalian brain," consisting of the cerebral cortex. Reptiles, being cold blooded animals, can survive in hypothermic conditions that unprotected humans, the "naked apes," would find intolerable. Consistent with that distinction, the reptilian brain is more capable of surviving in an unbalanced physiological state than the mammalian brain. A reptilian brain might be able to function partially in bodily states of hypothermia, acidosis, hypoxia and/or hypoglycemia, while the higher cerebral centers require more metabolic energy to function correctly.

Another way to look at the relationship of the reptilian and mammalian brains would be to visualize two computers linked together. The mammalian computer or upper cerebral cortex is an advanced, large-volume storage system that can process massive amounts of information at moderate speed. This large-volume computer has one major weakness: it requires a steady, "high-voltage power supply" of glucose and oxygen, requiring 20 percent of the cardiac output at any given time. This design limitation means that in cardiac arrest the "mammalian computer" fails usually within 10 seconds of the cessation of blood flow to the brain.

The second or reptilian computer, located in the pons, geniculate bodies, and a portion of the occipital cortex, is a "prototype model" that requires a low-voltage power supply. The reptilian computer is quicker than the mammalian computer because it operates on instinct and less analysis of facts, but the reptilian computer is a bit inefficient in processing facts. The reptilian computer has a logic program that lacks clear concept processing, is ritualistic, and occasionally solves problems quickly with intuition rather than proven hard data. The reptilian computer printout is written in the language of "nonordinary reality" and is individualistic, nonconsensual, and dreamlike.

The mammalian and reptilian brains are interconnected and involved in joint projects most of the time. The mammalian brain, made up of the cerebral cortex, is the predominant computer producing an overall operative state of consciousness, which overrides the subconscious effects of the reptilian computer. During sleep, syncope, coma, psychotic episodes, and hypnotic trances, portions of the cerebral cortex can become dormant, allowing the reptilian brain to become the predominant computer. 


\section{The Near-Death Experience in Neurological and Psychological Terms}

Can the above mammalian and reptilian brain model help us explain near-death experiences on a neurological, physiological, or psychological basis? Let us review Moody's typical 15 events of the NDE from this perspective:

1. The individual experiences clinical death. This is a rather simple physiological event. The heart stops and blood flow to the brain ceases. Within 10 to 30 seconds, the cerebral cortex is severely disturbed as its essential supply of oxygen and glucose is all but stopped, and the individual becomes unconscious. The mammalian computer is no longer "on-line" and can no longer override the reptilian computer. Unfortunately, the reptilian computer is also undergoing a "power failure." However, because of its ability to operate during a "brown-out," or in a poor metabolic environment of hypoxia, acidosis, hypercapnia, and hypoglycemia, the reptilian brain can still function in an altered mental state, prior to total brain death. Without the overriding influence of the cerebral cortex, the pons, geniculate bodies, and primitive occipital cortex are free to take charge of the perceptual and creative powers of the unconscious person.

If nothing is done for this individual to reverse the evolving biological death within four to six minutes, the cerebral cortex will fall into irreversible cellular death, and if a lack of cerebral blood flow continues for another estimated 15 to 60 minutes, the pons and brain stem will become functionless and die. At that point all diagnostic signs of death will be present and the individual will perceive nothing, as the black void of death ends his or her life; the individual will no longer perceive a near-death mental experience. However, if an effective, clinical intervention such as cardiopulmonary resuscitation (CPR) or advanced life support (ALS) is carried out prior to irreversible biological brain death, or if the heart and lungs spontaneously restart without clinical intervention, the individual will survive and experience an NDE, particularly if certain neurologic pathways, described below, are activated. Cerebral function and consciousness then return.

The current literature on near death events is based on the experiences of people who may have been clinically dead, but who did not undergo terminal biological brain death. We do not know for certain whether people who die and develop terminal biological death have NDEs prior to the time of their demise. 
2. The individual hears the voices of doctors or relatives as he or she departs. It is well known to anesthesiologists that hearing is the last sense to be anesthetized prior to surgery and the first sense to return in the recovery room (Cherkin and Harroun, 1971; Levinson, 1965). Surgeons, anesthesiologists, and nurses have learned to be careful not to say any socially regrettable remarks about a patient while the patient is recovering from the effect of a general anesthetic.

B. W. Levinson (1965) falsely suggested into the ears of ten surgical patients who were in a deep plane of anesthesia that an anesthetic crisis was occurring. One month later these same patients were hypnotized and regressed to the time of the operation. Four patients remembered the exact words describing the crisis. Four others became very anxious, were brought out of the hypnosis, and reported remembering some words that were spoken at the time of surgery. Two patients remembered nothing. Arthur Cherkin and Phyllis Harroun (1971) noted that strong statements made around some patients while coming out of anesthesia produced unpleasant memory traces after the patient was fully alert. Both of these two studies suggest that hearing can be operational when the patient is in a subcortical state.

The use of anesthesia is a situation of controlled blunting of the intellect and senses. Anesthesia starts by making the cerebral cortex unconscious, and then progresses to the loss of many functions at stage II of anesthetic induction. Anesthesia finally leads to the total dysfunction of the medulla oblongata in stage IV, causing cessation of breathing and cardiovascular function and death of the individual. It might be said that the controlled use of anesthesia to stage III is very close to clinical death except that the heartbeat and respiratory pattern are retained.

When sudden syncope or unconsciousness occurs, usually because the heart stops secondary to some intrinsic cardiac arrhythmia, the cerebral cortex is the first brain structure to fail. Patients will usually have fixed and dilated pupils almost immediately after unconsciousness develops. The pupillary dilation mechanisms are tied to the third cranial nerve, which is derived from structures of the mesencephalon, or midbrain. Some agonal respiratory patterns noted in many dying patients suggest that the function of the medulla oblongata is still available for a short time after cerebral unconsciousness.

It is of considerable interest that the auditory nerve or cranial nerve VIII leaves the brain at the lower level of the pons. If we consider the sequence of brain death in most standard instances of sudden death, we might suggest the following order: first, cerebral-cortical dysfunction and clinical death of the mammalian brain, leading to 
unconsciousness; second, midbrain dysfunction with failure of the oculomotor nerve (cranial nerve III) and resultant pupillary dilatation; third, dysfunction of the pons with failure of the cranial nerves V, VI, VII, and VIII, and cessation of hearing; and fourth, medullary dysfunction with loss of cranial nerves IX, X, XI, and XII, and cessation of all respiratory movements and cardiovascular reflex function.

This division of the central nervous system into these four sequentially impaired sections can be considered as parts of an evolutionary continuum. The division can also be considered to represent four separate computers with varying abilities to survive or function in a disordered neurological state, as occurs in anesthetic induction or sudden death. If hearing is the last sense to disappear during induction of anesthesia at stage II prior to medullary dysfunction, would it be possible, after sudden clinical death has struck a patient but before total biological brain death occurs, that structures in the pons would still function in a hypoxic state and without the overriding influence of higher cerebral functions? If that is the case, then a nearly dead person would still hear the doctors and nurses talking about his or her demise or a need to start emergency care.

3. The individual hears an uncomfortable, loud buzzing or ringing noise. At this stage further function and metabolic decay within the pons or failing cortical override might cause sound to be processed in an imperfect way, giving rise to uncomfortable or loud sound perception. It is important to remember at this point that the person who undergoes a near-death experience does not really die, except in the sense of passing into a state of clinical death. At some point in the neardeath experience, adverse physiological states are reversed, and the body normalizes, causing consciousness to reappear. As consciousness reappears, some mechanism must be present to "re-light" the cerebral cortex.

On the other hand, if no physiological improvement occurs within six minutes, irreversible and permanent biological brain death occurs. Under these circumstances, if we were to take a purely mechanistic view of death, excluding religious concepts, death would be the end of all human perception, and a black void of nothingness would settle over the body. Thus, hearing conversation of people around the deathbed converts to imperfect, uncomfortable noises, which in turn converts to nothing as death is finalized.

It is of major religious interest that The Tibetan Book of the Dead (Evans-Wentz, 1957) described death in a very similar fashion to that suggested in the above paragraph. Tibetan monks are frequently summoned to perform chants and religious services while a dead person lies 
in state in his or her home. Monks are taught that the dead person has a disturbed sense of hearing, and the monk must chant to soothe and encourage the dead person to relax and submit to death, so that he or she can pass down the right path in the afterlife for later rebirth.

4. The individual moves through a long dark tunnel toward a bright light. After the above three steps, we assume that a favorable therapeutic event occurs, either by physician intervention or by some spontaneous means, and the cerebral cortex returns to "on-line function." If we consider that the nearly dead human is now undergoing a physiological improvement and the cerebral cortex/computer is being repowered from a functional and metabolic standpoint, then the experience of passing through a dark tunnel might represent a stored memory.

Consider that the cerebral cortex is like a computer memory bank, which stores important information for the purpose of survival and must store those bits of information in some organized sequence. When power is cut off, well-designed computers have safeguards to prevent the total loss of stored data, so that when the silent computer is repowered, the bits of information are restored, the restoration following a certain electrical sequence that is inherent to the design of the computer or the working program.

Is it possible that as a cerebral cortex is "re-lit" during the neardeath experience, previous memories (bits of stored information) are flashed before the individual, starting with the first memories stored in the cerebral cortex and moving toward newer memories? Educational psychologists have learned that human decisions under stress are conditioned to fall back on first learned behavior. When a threatening problem appears, appropriate analysis and action must be taken quickly for survival of the individual. Thus, first learned experiences stored in the brain may be strong motivators of perception and behavior.

It had been conjectured previously that the tunnel of darkness was a replay of the birth experience (Sagan, 1979): a newborn lives in a warm, comfortable, intrauterine environment for nine months and then, through a very traumatic experience, it is born into the light. It is also curious that many so-called "astral projectors" perceive that they are squeezed out of their bodies through the top of the head. Since most people are born with cephalic presentations, we might expect any sensations associated with astral projection to be through the head. What would be the perception of "out-of-body" projection for an individual who was delivered by Caesarean birth? Susan Blackmore (1983) collected a group of 22 people who were born by Caesarean section and who had also experienced an NDE later in their lives. The group was asked about the nature of the sensations noted during their NDEs, including the 
presence of a "tunnel of light." Most individuals born by Caesarean section and free of the trauma of vaginal delivery described a "tunnel of light" sensation, very similar to those persons delivered by conventional vaginal presentations. Blackmore concluded that the birth experience analogy for NDEs was superficially appealing but unhelpful.

Thus it appears that the "tunnel of light" is not a repressed memory of vaginal birth. Could the darkness, a light at the end of the tunnel, vibrations, uncomfortable noises, and a sensation of rotation be a representation of intrauterine life? The fetus tumbles within the womb and is exposed to a variety of loud maternal sounds, such as bowel sounds or the pulsatile sounds of blood rushing through the placenta or the maternal aorta. In a liquid medium, such sounds would indeed be very loud as perceived by the fetus. Perhaps the light at the end of the tunnel is what the intrauterine fetus sees and is related to the stimulation of central vision in the retina. Such a hypothesis would explain why a child of a Caesarian birth experiences the same NDE as a child of a vaginal birth.

But there may be other ways to look at the tunnel of darkness and the bright light at the other end, particularly for those who actually die. Gurus in India, who for centuries have perfected transcendental meditation, see the tunnel and the "white light" as the great and divine energy called kundalini, which is found in every human being. Hindu religious scriptures teach that there is not just one human body, but four (Muktananda, 1995): the first is the familiar physical body; the second is the "subtle body" representing the state of mind called the "dream state"; the third is the "causal body" where deep sleep is found; and the fourth is the covering of the individual soul, called the "Blue Pearl" or the "supracausal body."

The goal of transcendental meditation is to move from the physical body through waking, dreaming, and deep-sleep states to the "Blue Pearl," where the meditator can enter a world of death, meeting ancestors and experiencing heaven or hell. The "Blue Pearl" sounds like a perfect description of a near-death experience. Master yogis can develop cardiac arrest or profound bradycardia while in very deep states of meditation (Kothari, Bordia, and Gupta, 1973a, 1973b). Do we become a pure soul when we meditate, project out of the body, or fall into a neardeath experience, passing through a tunnel of light as a transitional state?

5. The individual experiences moving outside the normal physical body. Newborn infants are not able to say how it feels to be free to move about in a big, new world following delivery. It probably is not a 
pleasant experience to be born and separated from the womb, which has served as a tightly adherent home for the fetus for nine months. A fetus might be conditioned during its intrauterine life to accept the lining of the womb as a part of its own body. Thus, the infant might perceive birth and separation from the womb as an out-of-body experience (OBE).

6. The individual sees the physical body from an external vantagepoint. People who project out of the physical body sometimes see it from a distance and are frequently connected to the physical body by a cord. Adult astral projectors are sometimes fearful that if that connecting cord is severed there would be no way for the metaphysical body to reunite with the physical body, and death would follow. Are there any possible scientific explanations for out-of-body experiences?

Birth is likely an unpleasant experience for a newborn that has enjoyed nine months in a warm intrauterine environment: suddenly, there is intense pain, as the tight constricting squeeze of birth sets in, followed by separation from warmth into a cold, hostile environment, and severing of the umbilical cord. All these birth events represent a very traumatic introduction to worldly life. Is the birth experience so terrible that an early, conditioned, lifelong fear is placed in the minds of all human beings? Is this birth trauma stored in the brain as an important early primordial image that can be recovered during special mental conditions induced by meditation, hypnosis, astral projection, or NDEs, allowing early fears to surface without the rational control of the cerebral cortex?

During rapid eye movement (REM) sleep, which occurs in discrete periods several times a night, human beings experience two important neurological changes. The cerebral cortex falls asleep and the body is essentially paralyzed; spinal sensations from the entire body cease when the REM center, located in the pons, is stimulated and operational. We "toss and turn" in nonREM sleep; but during REM sleep, we have increased movement of the eyes, while the body holds a motionless, paralyzed posture.

Perhaps our arboreal ancestors, while dozing on the branch of a tree, used REM sleep to scan their environment by listening for predators. A motionless sleeper was able to listen better, was harder to detect, and was less likely to fall out of the tree. The idea that an animal can scan the environment for impending dangers while asleep is not a far-fetched hypothesis. Birds in dangerous situations can use what is called "unihemispheric slow-wave sleep" to remain vigilant for predators while one half of the brain sleeps, keeping one eye open in the direction from which a predator is likely to approach; ducks at the edge 
of a sleeping group both oriented their one open eye away from the group's center and markedly increased unihemispheric slow-wave sleep compared with ducks in the center of the group (Rattenborg, Lima, and Amlaner, 1999). With this type of sleep a bird can "keep an eye out" for predators and decide to awaken the rest of the brain fully if a major survival response is needed.

Humans maintain an upright posture in a gravitational field, and the entire human neurological system has adjusted to the gravitational field of our environment. As we develop over the years, humans learn to interpret peripheral gravitational sensations into our spatial interpretation of the world. Using this spatial adjustment, we know up from down and right from left as we ambulate along the ground. In order to stay on path, we have to use our neurological system as part of our environmental awareness. During REM sleep, the reptilian brain is stimulated. Conscious cerebral awareness is blunted, and peripheral spinal sensations are gone. From a perceptual standpoint, we are only a midbrain, hooked to hearing, in a state of nonordinary reality. Neurologically, we have passed into a world without gravity. Our midbrains do their best to interpret this new disorienting state with a resultant OBE. In fact, our body is gone from a sensory standpoint because we have no spinal sensory ability, and our rational, conscious mind is also gone. Illusory free floating becomes possible, if not mandatory, because we have lost all our normal spatial clues.

Pilots experience many disturbing illusions while flying at night or in overcast weather. These flight environments also cause the pilots to lose many of their spatial cues, normally based on vision. For years, the U.S. Navy has placed their student pilots and flight surgeons in a dark room with a tiny red light fixed on a wall. The students are asked to focus on the light, and after a few minutes, they perceive the light as moving in an erratic, random way, a phenomenon called autokinesis (DeHart, 1996). Autokinesis occurs when visual cues are reduced; the movement is an illusion seen by the students because their eyes drift in an involuntary way as a response to visual deprivation. Is an OBE a nonordinary response to total tactile-sensory deprivation, as the midbrain becomes the only active mental operative during a NDE?

7. The individual experiences a state of emotional upheaval. As noted above, it is likely that the newborn infant undergoes a period of emotional upheaval once it is removed from the warm uterine vault that has conditioned it to a sense of emotional well-being during nine months of consistency and permanency. This emotional upheaval is 
actually healthy at the time of birth, since it causes the child to cry, which in turn stimulates heavy breathing following the birth ordeal. Heavy respiratory efforts encourage oxygen delivery to the lungs and increase the partial pressure of oxygen in the arterial system, ensuring that all hemoglobin molecules in the red blood cells are saturated with oxygen for speedy, efficient delivery to the newly functional cerebral cortex.

In the NDE, a period of emotional upheaval may mean that the corpus callosum is becoming incompletely stimulated as cerebral perfusion is restored. Emotional upheaval may come from the interaction of a fully operational pons and a recovering but inefficient cerebral cortex-a heavy dose of "nonordinary reality" from the lower computer at a time when the refined upper computer is not fully able to analyze and function normally.

8. The individual accommodates to a new, strange nonphysical body and may discover the power of mental telepathy. What kind of human personality would arise if a primitive occipital cortex, corpus callosum, midbrain, and pons were the major functional brain components? There would be a combination of "nonordinary reality" with emotions. On top of this unique mental perceptual unit, there might be the addition of universal vibrations striking a free, but otherwise intact auditory apparatus. Would that produce a human capable of making instinctive survival decisions based on a "sixth sense?" Would pure animal intuition, unclogged by the overriding influence of the analytical, rational mind of the higher cerebral cortex, be the dominant, functional mental process during the NDE?

Animals thrown into a raging blizzard instinctively seek warmth and a protected place. Humans also are driven by instincts to seek protection, but a well-educated human can "think" his or her way through the same problem, make a poor cerebral decision and freeze to death, violating every good law of nature. Intuition allows us to take action without recourse to reason. Knowledge based on intuition is an innate, instinctive insight, frequently tied to an emotion, such as fear, joy, or hate. The insight and emotion are perceived as appropriate and achieved without the benefit of analytically derived data.

Moody (1975) described the case of a blind man who lost his vision in childhood, but who suddenly could see his surroundings accurately during his NDE. However, the patient found himself blind again when he returned to consciousness. The blind man accurately described his surroundings, the appearance of individuals, and the events that transpired, apparently perceived in a telepathic fashion 
while comatose. Those apparent telepathic skills were lost when consciousness returned, and the man was again blind after his NDE was over.

Kenneth Ring and Madelaine Lawrence (1993) presented evidence for veridical out-of-body perception. They cited an anecdotal report by Kimberly Clark in which a heart attack victim admitted to a Seattle hospital had a sudden cardiac arrest and developed an NDE with an OBE. She drifted outside and noted an old tennis shoe on a ledge along the third floor of the hospital, which was not visible from her hospital room. The patient survived and later told Clark the location of the shoe, along with particular details about its condition and appearance. Being curious, Clark searched for the tennis shoe and found it in the exact location and physical appearance as the patient had described. Ring and Lawrence described comparable cases they collected of apparent accurate out-of-body perception during NDEs, which many skeptics would discount as coincidence.

Chance surprises seem to appear like magic. NDEs are strange, unbelievable events that happen when the brain is undergoing stress and confusion, but there is always the probability that some impressions seen in the NDE can later be connected to actual fact. Odds sometime favor believing that two facts are related when, in truth, they are not. If you believe that an NDE is a product of some portion of the subcortical brain and that OBEs and veridical perceptions are real, then only hearing would be available as a sensory input during the OBE.

If hearing is intact during NDEs and deep planes of anesthesia, could the sense of hearing become a prime collector of data for the intuitive mind and the mediator for many apparently telepathic and parapsychological phenomena? Hearing is processed initially in the pons, where various neural tracts can interconnect with other senses. Through these neurological pathways, could blind persons, particularly those who had adequate sight at some point, be taught to "see" through the sense of hearing?

Synaesthesia is a phenomenon in which one type of sensation evokes the perception of different sensation, as when the hearing of a sound results in the sensation of the visualization of a color. Some individuals perceive color when they hear spoken phases, words or letters, phenomena respectively called chromatic-lexical synaesthesia, chromaticgraphemic synaesthesia, and chromatic-phonemic synaesthesia. There are case reports in the medical literature of individuals who see distinct colors with the striking of specific notes on a piano (Baron-Cohen, Harrison, Goldstein, and Wyke, 1993; Koike and Yoshino, 1990). 
It is a common experience of elementary school children in music appreciation classes to be asked by a teacher to put their heads on their desk, relax, and shut their eyes while classical music is played. These children can very quickly have visual images appear in their heads through the power of imagination and the stimulation of music. This type of skill is called eidetic imagery, in which previously seen or imagined objects can be visualized, and it can be quite advanced in some people. A study by Joseph Glicksohn, Orna Salinger, and Anat Roychman (1992) evaluated ten subjects for possible eidetic and/or synaesthetic ability, and discovered that both structural and typographic eidetic imagery were correlated with synaesthesia, indicating that the two phenomena are related.

There may be another physiological mechanism besides synaesthesia or eidetic imagery to explain how a previous sighted but now blind individual could see during a period of abnormal brain function induced by an NDE. In primates, the retina is connected to multiple locations in the cerebral cortex by several parallel pathways. The largest pathway is the geniculo-striate pathway, which connects the geniculate nucleus to the striate cortex. If this pathway is damaged, blindness to part of the visual field is noted. However, other parallel visual pathways are left in place to function. Using behavioral forced-choice techniques, studies have shown that visual discrimination can be sustained through extrastriate pathways, an unusual ability called blind-sight (Weiskrantz, 1990). Such blind subjects are unaware of any visual stimuli, but are able to perform remarkable visual discriminations at very high levels of proficiency.

In the blind man reported by Moody (1975), major visual pathways had always been disabled by some disease process. However, the blind man's parallel visual pathway was intact and functional. One could speculate that during an NDE, the secondary parallel visual pathways are stimulated and allowed to function to produce a state of blind-sight, allowing blind persons to see their surroundings and report accurately what they truly "observe" during their NDE.

9. The individual visualizes dead spirits or dead relatives, who may act as guides. It is assumed that at this point some medical intervention has begun to improve the function of the lower portions of the brain where early childhood memories are stored about the care received from mother, father, grandmother, grandfather, aunts or uncles, people who may frequently be dead at the time the adult patient develops cardiac arrest. Primitive early childhood memories of infant care and guidance by caring adults, which are normally suppressed by the adult mind, are 
now free to be recognized since the adult, cerebral mind is still not fully operational.

It is interesting to note that most people visualize dead people in NDEs; and that this is also true for small children who have had little experience with older relatives who have died. By contrast, delirious, obtunded patients usually hallucinate living people and not dead persons. Can the two-brain model explain why the near-death experiencers visualize the dead, while obtunded individuals hallucinate the living?

The upper cerebral cortex is designed for careful, critical analysis during conscious thought, while the subcortical brain, which deals in survival issues, is quick, instinctive, and reactive. If our brain wanted to store information about death, what would be the most efficient way to wire the brain? We would probably not place a heavy dose of death in the upper cerebral cortex; none of us would be very efficient in our daily life if we constantly rehashed thoughts of death in our conscious personality. Doing so might produce constant anxiety, as seen in posttraumatic stress disorder (PTSD).

The signs and symptoms of PTSD occur after unexpected, overwhelming disasters involving serious survival issues for the participant. The victim relives and rethinks the event, developing chronic anxiety, hyperalertness, memory impairment, and insomnia. Patients with PTSD may complain of numbness in their responsiveness to other people and begin to feel emotionally dead. Has the subcortical brain run amuck in PTSD, forcing the cerebral cortex to deal with survival issues that are normally withheld from repetitive higher brain analysis? It would seem more natural to store thoughts of death in a subcortical area where survival elements are handled during a crisis like an NDE.

If the concept of death has been stored in this way, that might explain the differences between delirium and NDEs. In delirium, an obtunded individual may be oriented to person and place, but not time. There is some upper cerebral functioning going on, even if this function involves active hallucinations. If the cerebral cortex deals mainly with memories of living experiences, a delirious mind might attempt to sort out thinking, which is non-emergency in nature. The delirious mind is still able to override the REM center and the subcortical brain. In delirium, the cerebral cortex may sense a state of confusion and irritation, but it does not experience a threat of death. Thus, in delirium, hallucinations involving death are less likely to arise.

In NDEs, the cerebral cortex has physiologically shut down, and the subcortical region of the brain is no longer balanced by upper cortical analysis. The subcortical brain senses that the individual is in a lifethreatening situation and it functions freely to save the individual from 
that impending death. NDEs may be very similar to hypnagogic and hypnopompic hallucinations that occur at the onset of sleep or upon awaking. Electoencephalographic recording during hypnagogic periods show the immediate onset of a low voltage, fast record of REM sleep (Berkow and Fletcher, 1992). For this reason, it is very likely that the brainwave pattern of REM sleep occurs during NDEs.

10. The individual has a feeling of great warmth. Well-nurtured, peaceful infants should feel warmth; and at that point, euphoria may be the prevailing emotional tone. The body of an NDEr may also experience a feeling of warmth as medical interventions effect a significant cardiac output, which, in turn, generates an adequate peripheral circulation, physically warming the body again.

11. The individual meets a "being of light," which may resemble God or Jesus and who desires to pass judgment on the individual. In the Christian faith children under the age of six are frequently taught a general religious philosophy as an accepted way to discipline them. There is no need for corporal punishment or lengthy academic reasons for good behavior if a parent merely has to say, "Jesus does not love a bad child." Prior to age six, children are not commonly taught many details about death. They are told that dead relatives have gone to sleep so they could travel to heaven to be with God. Thus, the early childhood mind has developed ethereal concepts of heaven and hell, good and bad, and the potential judgment of Jesus or God at the point of death. The areas of the brain where such early abstractions are stored is "on-line" during this phase of the NDE.

12. The individual perceives an instantaneous playback of the events of his or her life. The playback may be described in two ways: it may be rapidly sequential, where the order of events in the life of the individual progress from past memories to the present; or it may be one huge flash of all stored memories projected on the "screen of the mind" at once. This step in the NDE can be conceptualized as the "re-lighting" of the memory bits of information stored in the cerebral cortex. Wilder Penfield (1975) electrically stimulated various parts of the outer cerebral cortex that were surgically exposed during attempts to relieve the symptoms of epilepsy on conscious patients under local anesthesia; he reported that certain areas of cerebral cortex when stimulated reproduced a memory and an emotional response to the memory. In an analogous fashion, a person during an NDE perceives the instantaneous or sequential re-lighting of all past experiences as the cerebral cortex regains its function.

13-15. The individual approaches some type of barrier between life and death; finds he or she must return to life while overcome with love, joy 
and peace; and reunites with the physical body and becomes conscious. These last three steps are the final stages of the "re-lighting" of the cerebral cortex and the return of conscious awareness.

\section{Conclusion}

Some near-death researchers have interpreted accounts of unusual near-death experiences as evidence for the existence of heaven-or the existence of hell, since some people have taken unpleasant trips into a dark abyss (Greyson and Bush, 1992) - on the assumption that NDEs could not be explained through accepted knowledge of physiology. However, this paper suggests that physiological explanations for NDEs are possible, particularly if creative, speculative, scientific fantasy is also allowed.

Millions of Christians worldwide believe in God, Jesus, the Bible, and the concept of heaven and hell-all accepted religious concepts in which these followers have found comfort over the centuries. Initial near-death research seemed to suggest there might be scientific observations that would reassure religious people everywhere of the existence of God and a beautiful afterlife. Many books on NDEs have become best-sellers because readers want to believe that a pleasant hereafter awaits them and that immortality is scientifically possible, thereby lessening and making humanly tolerable our fear of death.

Initially Moody (1975) did not believe that NDEs were merely medical symptoms associated with a sequence of mental dysfunction, which could result from physiological events such as cardiac arrest, frightinduced vagal bradycardia, hypothermia, hypoglycemia (as in the case report presented above), and cerebral metabolic aberrations. However, in his latest book, Moody (1999) has disavowed the idea that NDEs have anything to do with an afterlife. Hypoxia, cerebral ischemia, profound acidosis, or certain pharmacological agents such as ketamine are other causes of the NDE, which can be seen as a dissociative mental state (Jansen, 1990, 1997). This dissociative mental state can occur in a setting of potential death with obvious decay in cardiac function, and it can also occur when patients have altered mental function but are not in danger of dying. Justine Owens, Emily Cook, and Ian Stevenson (1990) examined the medical records of 58 patients who reported NDEs during a significant illness or injury, or whom 28 were truly facing death, while 30 were in no danger of dying (like the patient presented in this paper).

This paper suggests that there are enough physiological facts presently available to begin to unravel the mystery of NDEs along scientific 
and psychiatric lines. Near-death experiences are not rare. They have frequently been estimated to occur to about a third of patients who are near death. Recent evidence suggests that the actual incidence is closer to half that (Greyson, 1998). A nationwide Gallup poll suggested that NDErs make up 5 percent of the entire adult American population (Gallup and Proctor, 1982).

Near-death experiences may even be the reason religion developed. Imagine a primitive, prehistoric tribe in which a medicine man has pronounced a tribal member dead, and the elders prepare a funeral ritual, certain of the mortal consequences. But the lifeless victim suddenly arises and, much to the astonishment of the tribal elders, begins to tell of mental travels to a strange and beautiful place. The elders cannot explain how this resurrection of the dead has occurred and, perhaps to insure their dominant position in the tribe, they invent the concept of God and an afterlife, and explain that only they can interpret God for the rest of the tribe. Thus, the children of the tribe are taught religious concepts to store in the primitive centers of their minds. If one of these children later becomes near dead, his or her mental trip to a beautiful place may be enriched by a spiritual visit with God, proving to the tribe that the elders were right and God exists. Over time, each NDE strengthens the human belief in God, while subsequent NDEs, enriched by that belief, become more sophisticated.

Allan Kellehear (1993) has suggested that NDEs may be culturebound phenomena, confined largely to societies where historic religions are dominant; he found social and historical explanations even more persuasive in explaining near-death phenomena than biological explanations. Thus, we might ask which came first, God or the NDE? Is religion the product of an occasional physiological mental aberration that needed a social explanation, or have learned religious concepts produced the modern near-death experience? Is the near-death experience an example of spiritualism affecting abstraction, or of abstraction influencing spiritualism?

\section{References}

Baron-Cohen, S., Harrison, J., Goldstein, L. H., and Wyke, M. (1993). Coloured speech perception: Is synaesthesia what happens when modularity break down? Perception, $22,419-426$.

Berkow, R., and Fletcher, A. J. (Eds.). (1992). The Merck manual of diagnosis and therapy (16th ed.). Rahway, NJ: Merck Research Laboratories.

Blackmore, S. J. (1983). Birth and the OBE: An unhelpful analogy. Journal of the American Society for Psychical Research, 77, 229-238. 
Brinkley, D., and Perry, P. (1994). Saved by the light. New York, NY: Harper Collins.

Cherkin, A., and Harroun, P. (1971). Anesthesia and memory processes. Anesthesiology, $34,469-474$.

DeHart, R. L. (1996). Fundamentals of aerospace medicine (2nd ed.). Baltimore, MD: Williams and Wilkins.

Eadie, B. J., and Taylor, C. (1992). Embraced by the light. Placerville, CA: Gold Leaf Press.

Evans-Wentz, W. Y. (Ed.). (1957). The Tibetan book of the dead. New York, NY: Oxford University Press.

Gallup, G., and Proctor, W. (1982). Adventures in immortality: A look beyond the threshold of death. New York, NY: McGraw-Hill.

Glicksohn, J., Salinger, O., and Roychman, A. (1992). An exploratory study of syncretic experience: Eidetics, synaesthesia and absorption. Perception, 21, 637-642.

Greyson, B. (1998). The incidence of near-death experiences. Medicine and Psychiatry, 1, 92-99.

Greyson, B., and Bush, N. E. (1992). Distressing near-death experiences. Psychiatry, 55, 95-110.

Jansen, K. L. R. (1990). Neuroscience and the near-death experience: Roles for the NMDAPCP receptor, the sigma receptor and the endopsychosins. Medical Hypotheses, 31, 2529.

Jansen K. L. R. (1997). The ketamine model of the near-death experience: A central role for the N-methyl-D-aspartate receptor. Journal of Near-Death Studies, 16, 5-26.

Kellehear, A. (1993). Culture, biology, and the near-death experience: A reappraisal. Journal of Nervous and Mental Disease, 181, 148-156.

Koike, H., and Yoshino, Y. (1990). Polyesthesia: Report of two cases. Clinical Neurology, 30, 193-198.

Kothari, L. K., Bordia, A., and Gupta, O. P. (1973a). Studies on a yogi during an eightday confinement in a sealed underground pit. Indian Journal of Medical Research, 61, 1645-1650.

Kothari, L. K., Bordia, A., and Gupta, O. P. (1973b). The yogic claim of voluntary control over the heart beat; An unusal demonstration. American Heart Journal, 86, 282-284.

Levinson, B. W. (1965). States of awareness during general anaesthesia states. British Journal of Anaesthesia, 37, 544-546.

Moody, R. A. (1975). Life after life. Covington, GA: Mockingbird Books.

Moody, R. A. (1999). The last laugh: A new philosophy of near-death experiences, apparitions and the paranormal. Chartottesville, VA: Hampton Roads.

Muktananda, S. (1995). Does death really exist? (2nd ed.). South Fallsburg, NY: SYDA Foundation.

Osis, K., and Haraldsson, E. (1977). At the hour of death. New York, NY: NY: Avon.

Owens, J. E., Cook, E. W., and Stevenson, I. (1990). Features of "near-death experience" in relation to whether or not patients were near death. Lancet, 336, 1175-1177.

Penfield, W. (1975). The mystery of the mind: A critical study of consciousness and the human brain. Princeton, NJ: Princeton University Press.

Rattenborg, N. C., Lima, S. L., and Amlaner, C. J. (1999). Half-awake to the risk of predation. Nature, 397, 397-398.

Ring, K., and Lawrence, M. (1993). Further evidence for veridical perception during neardeath experiences. Journal of Near Death Studies, 11, 223-229.

Sagan, C. (1979). Broca's brain: Reflections on the romance of science. New York, NY: Random House.

Weiskrantz, L. (1990). Outlook for blindsight: Explicit methodologies for implicit processes. Proceedings of the Royal Society of London (Series B: Biological Sciences), 239, 247-278.

Whinnery, J. E. (1997). Psychophysiologic correlates of unconsciousness and near-death experiences. Journal of Near-Death Studies, 15, 231-258. 